\title{
Dealing with Venture Capitalists: Shopping Around or Exclusive Negotiation
}

\author{
Catherine Casamatta* Carole Haritchabalet ${ }^{\dagger}$ \\ July 11, 2011
}

\begin{abstract}
We study the problem of an entrepreneur who faces two investors with private information about his project's profitability. We analyze the entrepreneur's optimal negotiation strategy. Importantly, we assume that the entrepreneur derives a private benefit of control so that he cares not only about expected monetary profits, but also about the probability to obtain financing. We show that if the entrepreneur can shop around with each venture capitalist's offer, he obtains high expected monetary profits. If he commits to a period of exclusive negotiation with one venture capitalist, before opening negotiation with its competitor, he can increase the probability to obtain financing, although the deal terms are less favorable. For low levels of private benefits, the model predicts that venture capitalists' deal flow is high, but that only the experienced venture capitalist makes profits. For high levels of private benefits, expected profits increase for the unexperienced venture capitalist, while the deal flow and expected profits decrease for the experienced venture capital firm.

Keywords: deal flow, exclusive negotiation, venture capital, start-up financing, informed investors.

JEL codes: G2, G3, D8.

\footnotetext{
${ }^{*}$ Toulouse School of Economics (CRM-IAE \& IDEI) and Europlace Institute of Finance

${ }^{\dagger}$ Toulouse School of Economics (GREMAQ).

This paper previously circulated under the title "Competition Between Informed Venture Capitalists and Entrepreneur's Fund Raising Strategy". Special thanks to Bruno Biais, Denis Gromb, Philippe Marcoul, Thomas Mariotti, Soren Bo Nielsen, Alexander Stomper, Elu von Thadden and participants to the 6th bundesbank spring conference on Financing Innovation, the Econometric Society European Meeting, the ASSET meeting, the Vienna Symposium on Asset Management, the Searle Center Research Symposium on The Economics and Law of the Entrepreneur, and the MOVE workshop on venture capital. Financial support from the Agence Nationale de la Recherche (ANR-09-BLAN-0358-01) is gratefully acknowledged. E-mail: catherine.casamatta@univ-tlse1.fr, carole.haritchabalet@univ-tlse1.fr. Corresponding address: Université de Toulouse I, 2 rue du Doyen-Gabriel-Marty 31042 Toulouse Cedex, France.
} 


\section{Introduction}

How should entrepreneurs negotiate with potential financial partners? Should they apply for funding to several venture capitalists simultaneously, raising the possibility to shop around with each competitor's offer? Should they initiate exclusive negotiation with one potential investor, and contact alternative venture capitalists only in case negotiation fails? What are the consequences of these strategies for venture capitalists' deal-flow and expected returns? This paper explores these questions, and derives the optimal negotiation strategy of entrepreneurs and the subsequent competition in the venture capital industry. These questions are natural in the context of entrepreneurial finance, because investment opportunities lie in private and unknown firms. Unless revealed by entrepreneurs, potential deals are not known to investors. As a consequence, the effectively competing investors are those contacted by entrepreneurs. The nature of competition and the corresponding profits of the venture capital industry is, at least partly, driven by the negotiation strategy adopted by entrepreneurs.

Exclusive negotiations are frequent in large takeover transactions. ${ }^{1}$ They are also prevalent in early stage financing, although such practices are harder to quantify in private investments. For instance, venture capitalists' term sheets sometimes include exclusive negotiation periods, whereby entrepreneurs commit not to initiate talks with other potential financial partners during a predetermined period. Also, Hsu (2004) reports that about two-third of early-stage firms receive only one offer (but he does not measure the number of investors an entrepreneur negotiates with). The benefit of exclusive negotiation is obvious for financial partners who are de facto protected from competitive pressure. The

\footnotetext{
${ }^{1}$ Boone and Mulherin (2007) estimate that half of major takeover transactions between 1989 and 1999 occurred through private negotiations with a single bidder.
} 
objective of this paper is to understand why it can also be beneficial for entrepreneurs.

In our model, entrepreneurs' strategy results from the combination of two assumptions. Firstly, entrepreneurs value monetary profits, and derive also private benefits from the realization of their projects. These private benefits can reflect entrepreneurs' satisfaction to see their idea developed. Alternatively, private benefits can stand for future reputation gains if the venture succeeds. Success can then increase entrepreneurs' perceived talent, and give them access to better job opportunities. The existence of non pecuniary benefits associated with entrepreneurial ventures has been documented in a survey carried out by Blanchflower and Oswald (1992). In a similar spirit, Hamilton (2000) and Moskowitz and Vissing-Jorgensen (2002) find low monetary returns on entrepreneurial investments, and interpret these results as evidence of the existence of private benefits. Secondly, venture capitalists have different levels of experience, that determine their ability to screen investment projects. ${ }^{2}$ Possible explanations are that venture capitalists acquire specific knowledge from their focus on industrial sectors, geographical areas, or simply from repeated investments (see Gompers (1996), Hsu (2004) and Kaplan and Schoar (2005)). As a consequence, more experienced venture capitalists are able to generate more precise information and to secure positive expected profits when competing with less experienced investors. This lowers the expected return that entrepreneurs can obtain when they negotiate with several venture capitalists simultaneously. Because they care also about expected private benefits, entrepreneurs might choose another fund raising strategy. Our analysis builds on this fundamental insight.

\footnotetext{
${ }^{2}$ There is large empirical evidence that venture capitalists are able to obtain specific information on their portfolio investments: see e.g. Sahlman (1988, 1990), Fenn, Liang and Prowse (1995), Gompers (1995), or Kaplan and Strömberg (2004).
} 
Specifically, we consider a venture capital industry composed of two potential investors with different screening ability and an entrepreneur in search of funds. The entrepreneur can choose one of two negotiation strategies. Either he decides to shop for deals, and sends his project to the two venture capitalists simultaneously. After observing a signal on the project's quality, each competitor sends an offer (reminiscent of the standard term sheets observed in the industry). The entrepreneur can then reveal offers to competitors, who subsequently decide whether to maintain their offer or not. The alternative strategy is when the entrepreneur starts exclusive talks with one venture capitalist. This first exclusive negotiation stage can last an infinite number of time periods, and at any time, agents can move to a second stage of non exclusive negotiation (i.e. by approaching a second VC). Our results are the following. If the entrepreneur chooses to shop around, a purestrategy equilibrium arises whereby the more experienced venture capitalist earns strictly positive expected profits. With exclusive negotiation, the equilibrium is characterized by the following feature: The entrepreneur accepts any offer at the exclusive negotiation stage, and his expected utility is equal to his expected private benefit. It is sustained by the second venture capitalist's belief that he is contacted only when the first venture capitalist is pessimistic about the project's value. Given this belief, if the initial offer is rejected and non exclusive negotiation takes place, the second venture capitalist does not bid aggressively. This in turn undermines effective competition.

Given the outcome of each generic strategy, we explore what is the optimal choice of the entrepreneur. When the level of private benefit is low, the entrepreneur cares more about monetary profits, and prefers to shop for deals. In this environment, each venture capitalist's deal flow is high but only the more experienced venture capitalist obtains positive profits. As the level of private benefit increases, the entrepreneur cares more about the 
probability to obtain financing. In that case, the entrepreneur opts for exclusive talks to maximize the probability to be financed. He then sends his project to the less experienced venture capitalist first. As a consequence, the deal flow of the experienced venture capitalist shrinks and so does his expected profit. In contrast, the profit of the less experienced venture capitalist increases compared to his level when the entrepreneur shops for deals.

At equilibrium, different negotiation regimes emerge according to the level of private benefit of the entrepreneur. This allows to derive empirical predictions relating the level of private benefit to offer characteristics. A first result of the model is that high private benefit entrepreneurs should receive less offers than low private benefit entrepreneurs. If one interprets the level of private benefits as future reputation gains if the venture succeeds, it is likely that reputation gains are larger for unknown or young entrepreneurs. An implication of the model is thus that unknown entrepreneurs should receive less offers. Also, they should obtain worse financing conditions, which is consistent with the finding that pre-money valuation is lower in single offer deals than in multiple offer deals (Hsu 2004).

Also, the results of the model allow to relate the expected level of experience of VCs to the number of offers received by entrepreneurs. Hsu (2004) finds that the average level of experience of VCs is lower when a single offer is received compared to when several offers are received by entrepreneurs. Our model offers an explanation to this phenomenon.

Another implication of the model is that the relative performance of venture capital funds depends on the nature of competition. Specifically, when competition is intense, more experienced venture capitalists should perform better than less experienced venture capitalists: This is in line with the findings of Kaplan and Schoar (2005) that venture capital 
funds performance is persistent. According to our model, this needs not be the case with exclusive negotiations. In that case, experienced venture capitalists can outperform or underperform less experienced venture capitalists. A last prediction is thus that the distribution of profits in the venture capital industry varies with the nature of competition.

The paper is organized as follows. Next section presents the related literature. Section 3 describes the model and derives the first-best level of investment. Section 4 studies the outcome of the "shopping around" game, whereby the entrepreneur approaches the two VCs simultaneously and can show each VC's offer to his competitor. Section 5 derives the equilibria of the "exclusive negotiation" game. Section 6 studies the optimal negotiation strategy of the entrepreneur, and explores the levels of profit and financing patterns of the venture capital industry. Empirical implications of our theoretical results are explored in section 7. Section 8 discusses the robustness of the results of the model to some changes in the assumptions. Section 9 concludes and proofs are provided in the appendix.

\section{Related literature}

Our paper is directly linked to the literature on competition between financial intermediaries with asymmetric information. ${ }^{3}$ Our analysis of the game when the entrepreneur shops for deals is close to the two-stage game analyzed by Broecker (1990). An important difference is that we study the case where information precision is heterogenous among investors. One consequence is that the most experienced venture capitalist earns positive profits (while all intermediaries make zero profits in Broecker (1990)). Another consequence is that investment is efficient in our setting, while it is not necessarily the case in

\footnotetext{
${ }^{3}$ See Rajan (1992), Sharpe (1990), Thakor (1996), von Thadden (2005), or Hauswald and Marques (2003) for various models of auctions between informed investors, and Milgrom and Weber (1982) for a general auction setting.
} 
Broecker (1990). Other papers study situations of informed investors and focus on the optimal contract design between investors and entrepreneurs: Inderst and Mueller (2006) and Peyrache and Quesada (2006) mainly study the case of a monopolistic informed investor, while Axelson (2007) and Garmaise (2007) study competition. Our assumptions allow to simplify the derivation of the optimal contract and to endogenize the nature of competition. A distinctive feature of our analysis is thus that we explicitly determine whether investors face competitors when making offers. This question is particularly relevant in the venture capital context where new investment opportunities cannot be easily spotted by venture capitalists.

Our emphasis on the trade-off between exclusive and non exclusive negotiation is also linked to the auction-negotiation trade-off of Bulow and Klemperer (1996). Our analysis shares their result that auction (i.e. non exclusive negotiation) maximizes the expected monetary revenue of the seller (i.e. the entrepreneur). But because the entrepreneur also enjoys a private benefit, which depends on the probability to obtain financing, he sometimes favors exclusive negotiation. An interesting feature of our setting is that although non-exclusive negotiation is efficient, it is not necessarily preferred by the entrepreneur. This is because the more experienced venture capitalist is able to capture part of the profits. This induces the entrepreneur to prefer exclusive negotiation when private benefits are high, because he increases the probability to obtain financing. This in turn leads to inefficiently high investment. Hellmann (2007a) studies the optimal negotiation process chosen by an entrepreneur to obtain resources. The main difference with our analysis is that Hellmann (2007a) assumes that investors (resource providers) can only be contacted sequentially, while we consider explicitly the trade-off between non exclusive (simultaneous contacts) and exclusive (sequential contacts) negotiation. In this setting, Hellmann 
(2007a) explores the incidence of screening costs on the provision of resources and on the efficiency of the negotiation process. We discuss the assumption of costly screening in more details in section 8 .

In our model, entrepreneurs can perfectly identify potential financial partners, and their matching with a financial partner results from their endogenous choice. A somewhat different view is proposed by the search literature applied to venture capital, where the probability to encounter a partner depends on a matching technology, and on the relative supply and demand for venture capital, as explored in Inderst and Mueller (2004). One result of their analysis is that venture capitalists make higher profits when competition is not too intense. Relatedly, we highlight the fact that profits are higher for a venture capitalist with superior information. Hellmann (2007b) analyzes the incentives of scientists and firms to engage in search activities to increase the probability of a match. He shows in particular how patents affect search intensity on both the scientists' and the firms' side. We abstract from these issues by assuming that matching occurs with certainty when entrepreneurs contact venture capitalists. In other words, financial resources and investor's time are always available for a new venture.

The current paper is also related to the literature on venture capital financing. A major difference is that we focus on venture capitalists' screening role, rather than on their monitoring and value-added activities. ${ }^{4}$ The fact that some venture capitalists are more experienced than others has also been largely documented. Papers have explored how the level of experience of venture capitalists changes their behavior. Bottazzi, Da Rin,

\footnotetext{
${ }^{4}$ See Schmidt (2003), Renucci (2008), Repullo and Suarez (2004), or Casamatta (2003) on the advising role of venture capitalists, and Chan, Siegel and Thakor (1990), Hellmann (1998), Dessì (2005) or Cestone (2006) on the control and monitoring exerted by venture capitalists.
} 
and Hellmann (2008a, 2008b) find that more experienced venture capitalists, and venture capitalists operating in "better" legal systems are more actively involved in their portfolio firms. Experience also affects the decision to syndicate (Lerner (1994), Hopp and Rieder (2006), Casamatta and Haritchabalet (2007), Cestone, Lerner, and White (2007)) or the decision to exit (Gompers (1996)). None of these studies aims at understanding how heterogeneity in experience affects the nature of competition in the industry.

\section{The model}

\section{Investment project and returns}

We consider a standard corporate finance model. An entrepreneur is endowed with a one-period innovative investment project. Innovative projects generally entail high potential returns, together with a high level of uncertainty. To capture these features, we make the following assumptions.

Firstly, the project return is risky. For simplicity, future cash-flows $\tilde{R}$ can take two values, depending on the state of nature. In case of success, the project generates a cash-flow $R>0$, while in case of failure, the project generates a cash-flow 0 . The probability of success depends on the quality of the project. Projects can be of two quality types: either good $(G)$ or bad $(B)$. If the project is good, success occurs with probability $p$. If the project is bad, the probability of success is zero. This assumption is used to lighten algebraic expressions without loss of generality. Last, the project requires an initial outlay, denoted $I$.

Secondly, there is some uncertainty regarding the true quality of the project. Initially, all agents share the same prior belief that the project is good, denoted $q_{0}$. To fit the situation of early-stage financing, we consider that the project is very unlikely to succeed. Formally, 
the net expected cash-flows conditional on the initial belief of the agents (denoted $N P V_{0}$ ) is negative, and the net expected cash-flows of the $G$-type project is positive. Assuming risk-neutral agents, and normalizing the riskless interest rate to zero, this implies:

$$
N P V_{0} \equiv q_{0} p R-I<0<p R-I
$$

\section{The venture capital industry}

The entrepreneur is cash-poor, and must raise $I$ from investors. Because $N P V_{0}<0$, he cannot raise funds from traditional investors, and turns to venture capitalists (denoted hereafter VCs). Thanks to their experience at financing early stage ventures, VCs are able to (imperfectly) infer the quality of new projects. ${ }^{5}$ We assume that VCs perform investment analyses and observe at no cost a signal related to the project's true quality. ${ }^{6}$ This signal can be either high $\left(s_{\alpha}=H\right)$ or low $\left(s_{\alpha}=L\right)$ and is all the more precise that the venture capitalist's expertise $\alpha$ is high. Formally, the signal $s_{\alpha}$ observed by a venture capitalist with expertise $\alpha$ has the following properties:

$$
\operatorname{Pr}\left(s_{\alpha}=H \mid G\right)=\operatorname{Pr}\left(s_{\alpha}=L \mid B\right)=\alpha,
$$

where $\alpha>\frac{1}{2}$. After observing their signal, VCs update their belief on the project quality using Bayes' rule. We denote $q\left(s_{\alpha}\right)$, the posterior probability that the quality of the project is good given that a VC with experience $\alpha$ has observed a signal $s_{\alpha}$, and $N P V\left(s_{\alpha}\right)$ the corresponding net present value, conditional on the signal $s_{\alpha}$.

The industry is heterogeneous, with some VCs of type $\alpha=e$ (where $e$ stands for experienced) and some VCs of type $\alpha=u<e \leq 1$ (where $u$ stands for unexperienced).

\footnotetext{
${ }^{5}$ See Kaplan and Strömberg (2004) for a thorough analysis of the informational content of VC investment memoranda.

${ }^{6}$ Our analysis is immune to the introduction of costly signals: We discuss this issue in section 8 .
} 
This assumption captures realistic features of the industry, where some well-known and reputable venture capital funds compete with newer, less established funds. We assume that there are two VCs in the economy, one experienced and one unexperienced. ${ }^{7}$

We specify now the evolution of the project NPV conditional on signals. Firstly, any VC is sufficiently experienced so that the project NPV becomes positive conditional on observing a high signal. Were this not true, VC screening would be useless. Therefore, we have:

$$
N P V\left(H_{e}\right)=q\left(H_{e}\right) p R-I>N P V\left(H_{u}\right)=q\left(H_{u}\right) p R-I>0 .
$$

Secondly, to focus on the most interesting case, we assume that when screening by two VCs generates two opposite signals, the experienced VC's signal determines the sign of the project NPV. Extending the above notations to two signals, this means:

$$
N P V\left(H_{e}, L_{u}\right)=q\left(H_{e}, L_{u}\right) p R-I>0>N P V\left(H_{u}, L_{e}\right)=q\left(H_{u}, L_{e}\right) p R-I .
$$

From the investors' point of view, it is therefore optimal to undertake the project if and only if the experienced VC has observed a high signal.

\section{Entrepreneur's utility}

The entrepreneur derives utility from any financial return he receives from his firm, and also from running a successful firm. We thus assume that he enjoys a private benefit $B$, if the project succeeds. This assumption is in line with the literature on entrepreneurship, which considers the satisfaction derived from being an entrepreneur as one of the

\footnotetext{
${ }^{7}$ For sake of completeness, one could also consider the case of an industry where all VCs have the same level of -high or low- experience. We discuss this case in section 8 below. We also discuss how results are affected when more than two VCs exist.
} 
determinants of entrepreneurship. Blanchflower and Oswald (1992) document from survey data the existence of non pecuniary benefits in entrepreneurship. In a similar spirit, Hamilton (2000) and Moskowitz and Vissing-Jorgensen (2002) find low monetary returns on entrepreneurial investments, and interpret these results as evidence of the existence of private benefits. In our setting, the private benefit is only enjoyed in case of success. This can reflect a possible "stigma of failure" incurred by entrepreneurs who do not succeed (see Landier (2005)), or equivalently the reputation gains enjoyed by the entrepreneur if the firm goes on. Quite plausibly these expected future benefits are zero if the firm fails. Therefore the utility of the entrepreneur can be written:

$$
\begin{cases}U_{E}=R_{E}(R)+B, & \text { in case of success } \\ U_{E}=R_{E}(0), & \text { in case of failure }\end{cases}
$$

where $R_{E}(\tilde{R})$ denotes the entrepreneur's return when the project generates a cash-flow $\tilde{R}$.

\section{Timing of the game}

In the remainder of the paper, we study what investment policy can be achieved when signals are privately observed by VCs, and when entrepreneurs can design their negotiation strategy. The entrepreneur moves first, and chooses either to shop around or to start exclusive talks. The "exclusive talks" strategy means that the entrepreneur approaches one VC first. "Shopping around" means that he approaches the two VCs simultaneously. We solve the model backward. The next two sections detail the extensive form of each game, and analyze the outcome of each negotiation strategy. Section 6 determines the optimal negotiation strategy of the entrepreneur. 


\section{Shopping around}

Under this strategy, the entrepreneur approaches the two VCs simultaneously. We assume that each VC knows that a competitor has also been contacted. This corresponds to the view that venture capital is a small world. After being approached, each VC privately observes a signal on the project quality, and makes an offer to the entrepreneur. In our setting where the final payoff of the project is either $R$ or 0 , the choice of the financial contract reduces to a parameter $\gamma$, which represents the fraction of the firm's equity allocated to the entrepreneur when the venture capitalist invests $I .{ }^{8}$ This financial contract measures the post money value $\frac{I}{1-\gamma}$ proposed by a VC. The simultaneous competing bids are denoted $\gamma_{e}$ and $\gamma_{u}$.

After receiving offers, the entrepreneur can shop for deals, and show offers to competitors. In turn, each VC has the right to withdraw his offer at any time. This assumption captures standard industry procedures, whereby VCs propose term sheets that can be used by entrepreneurs to shop around. Such term sheets are typically non binding (i.e. these offers can be withdrawn).

Observing competitors' bids may induce VCs to make counter-offers. We rule out this possibility and assume instead that VCs commit on deal terms when making their offer. ${ }^{9}$ Note that in our setting, if VCs can change the content of their offer, as well as withdraw the offer itself, initial offers are just noise.

More precisely, the game considered is the following:

1. The two VCs privately observe their signal and make non binding offers $\gamma_{e}$ and $\gamma_{u}$.

\footnotetext{
${ }^{8}$ Focusing on contracts such that the entrepreneur is paid only in case of success is without loss of generality because only the expected profit matters for the entrepreneur. All offers giving the same expected utility to the entrepreneur are equivalent.

${ }^{9}$ This is equivalent to assuming that VCs make offers before observing their signal, and that they can withdraw their offer after observing their signal without modify the deal terms. This setting is explored in Inderst and Mueller (2006) where only one investor has private information.
} 
2. The entrepreneur shows (or not) each VC's offer to his competitor.

3. Each VC maintains his offer or not.

4. The entrepreneur chooses the most profitable remaining offer.

This setting is reminiscent of the two-stage game analyzed by Broecker (1990) with two differences: In our case, entrepreneurs can choose not to shop, and VCs have different expertise. We discuss below how these features modify the equilibrium. Define $\phi_{i}, i \in$ $\{e, u\}$ the probability that $V C_{i}$ maintains his offer. This probability depends on $V C_{i}$ 's signal and bid, and on his competitor's bid, if observed (we drop the arguments to lighten notations). A strategy for $V C_{i}$ is therefore a couple $\left(\gamma_{i}, \phi_{i}\right)$, with $\gamma_{i} \in[0,1] \cup \emptyset$, the strategy $\emptyset$ meaning that a VC does not make any offer.

To solve this game, it is useful to define each VC's maximum bid, $\hat{\gamma}_{u}$ and $\hat{\gamma}_{e}$. It is the bid such that each VC's maximum payoff when participating to the game is equal to his reservation utility. $V C_{u}$ 's reservation utility is simply zero when not participating. If VCs remove their offers after observing a low signal (this is indeed an equilibrium strategy as shown in the appendix), $V C_{u}$ 's maximum payoff is $N P V\left(H_{u}\right)$, i.e. the project NPV given that $V C_{u}$ has observed a high signal. $\hat{\gamma}_{u}$ solves:

$$
\begin{array}{cc} 
& \left(1-\hat{\gamma}_{u}\right) q\left(H_{u}\right) p R-I=0 \\
\Leftrightarrow \quad & \hat{\gamma}_{u}=\frac{N P V\left(H_{u}\right)}{q\left(H_{u}\right) p R} .
\end{array}
$$

The reservation utility of $V C_{e}$ is not zero, since the project has a positive value when he observes a high signal. He can therefore decide to bid 0: In that case, the entrepreneur 
accepts his offer when no other offer was made. $\hat{\gamma}_{e}$ thus solves:

$$
\begin{array}{cc} 
& \left(1-\hat{\gamma}_{e}\right) q\left(H_{e}\right) p R-I=\operatorname{Pr}\left(L_{u} \mid H_{e}\right)\left[q\left(H_{e}, L_{u}\right) p R-I\right] \\
\Leftrightarrow & \hat{\gamma}_{e}=\frac{N P V\left(H_{e}\right)-\operatorname{Pr}\left(L_{u} \mid H_{e}\right)\left[q\left(H_{e}, L_{u}\right) p R-I\right]}{q\left(H_{e}\right) p R} .
\end{array}
$$

Lemma 1 The maximum offer of the unexperienced $V C$ is smaller than the maximum offer of the experienced $V C$, i.e. $\hat{\gamma}_{u}<\hat{\gamma}_{e}$.

Lemma 1 simply reflects the informational advantage of $V C_{e}$ over $V C_{u}$. Because $V C_{e}$ 's signal is more valuable, he can afford to abandon a larger fraction of the firm's equity to the entrepreneur (equivalently the maximum pre and post money valuation is larger for the experienced VC than for the unexperienced VC). This result is not straightforward because of $V C_{e}$ 's outside option. The latter always has the option not to participate to negotiations, and invest in projects rejected by $V C_{u}$, which reduces his maximum bid as reflected in the right-hand-side of equation (3). The informational effect is larger than the outside option effect, which explains that $\hat{\gamma}_{u}<\hat{\gamma}_{e}$.

As a consequence, $V C_{e}$ has no incentive to bid more than $\hat{\gamma}_{u}$ and we call $\hat{\gamma}_{u}$ the competitive bid. If VCs could not observe each other's offer, $V C_{u}$ would be reluctant to offer $\hat{\gamma}_{u}$. That would induce $V C_{e}$ to offer a slightly better bid after observing a high signal, and $V C_{u}$ would end up investing in negative NPV projects (i.e. projects that received $s_{u}=H$ and $\left.s_{e}=L\right)$. The entrepreneur's ability to show offers to competitors alleviates the winner's curse for $V C_{u}$. In that case, $V C_{u}$ can offer a competitive bid, and maintain it only if $V C_{e}$ offers a lower bid. This induces $V C_{e}$ to also offer a competitive bid. A pure-strategy equilibrium arises because $V C_{u}$ is able to threaten to overbid $V C_{e}$ in case the latter offers too low a bid, without suffering from the winner's curse. This leads to the following proposition: 
Proposition 1 When the entrepreneur can shop around with competitors' offers, there exists a pure-strategy equilibrium such that both $V C_{e}$ and $V C_{u}$ offer $\gamma_{e}^{*}=\gamma_{u}^{*}=\hat{\gamma}_{u}$, and such that the entrepreneur shows $V C_{e}$ 's offer to $V C_{u}$. This equilibrium is sustained by the following probabilities $\phi_{u}$ and $\phi_{e}$ :

$$
\begin{aligned}
\text { i) } & \phi_{u}\left(s_{u}=H, \gamma_{e}<\hat{\gamma}_{u}\right)=1 \text { and } \phi_{u}\left(s_{u}=H, \gamma_{e}=\hat{\gamma}_{u}\right)=0 \\
\text { ii) } & \phi_{e}\left(s_{e}=H\right)=1 \forall \gamma_{u} \\
\text { iii) } & \phi_{u}\left(s_{u}=L\right)=\phi_{e}\left(s_{e}=L\right)=0
\end{aligned}
$$

The expected profit of $V C_{e}$ is strictly positive and equal to $I\left(\frac{q\left(H_{e}\right)}{q\left(H_{u}\right)}-1\right)$. The expected profit of $V C_{u}$ is equal to zero.

Proposition 1 implies that the entrepreneur is financed by $V C_{e}$ only, and that he is offered the maximum bid $\hat{\gamma}_{u}$. This is achieved thanks to the equilibrium strategy of $V C_{u}$ stated in condition $i$ ): The latter always withdraws his offer, unless $V C_{e}$ deviates from offering $\hat{\gamma}_{u}$. This induces $V C_{e}$ to offer $\hat{\gamma}_{u}$ for any signal observed, and to maintain his offer if he observes a high signal (condition $i i)$ ). Therefore, $V C_{u}$ never finances the entrepreneur at equilibrium. ${ }^{10}$ Last, condition $\left.i i i\right)$ states that VCs do not maintain their offer if they initially observe a low signal, because they attribute a negative NPV to the project.

Proposition 1 relies on the same intuition as in Broecker (1990). The ability of VCs to observe and withdraw offers alleviates the winner's curse and allows for pure-strategy equilibria. Our game has specific features not explored in Broecker (1990). Firstly, VCs have different levels of expertise, which allows $V C_{e}$ to make positive profits, while in Broecker (1990) all investors obtain zero profits. This captures a natural pattern of the VC industry, where better VCs obtain better deals (see Hsu (2004)). Secondly, offers are

\footnotetext{
${ }^{10}$ That will not be true when the entrepreneur decides to start exclusive talks, as shown in section 5 . Therefore, inexperienced VCs do finance projects in equilibrium in our model.
} 
not necessarily public in our setting, because that depends on the entrepreneur's equilibrium strategy. We show that at equilibrium the entrepreneur always shows $V C_{e}$ 's offer to $V C_{u}$. He does not need to show $V C_{u}$ 's offer to $V C_{e}$ though. This is because $V C_{e}$ 's strategy to maintain his offer does not depend on his competitor's offer. Our pure-strategy equilibrium is therefore not unique, but all pure-strategy equilibria lead to the same outcome.

Corollary 1 When the entrepreneur decides to shop around, investment is efficient, in the sense that all positive NPV projects (conditional on all available information) obtain financing.

The proof of corollary 1 is straightforward. Proposition 1 states that the project is financed if and only if $V C_{e}$ observes a high signal. By condition (1), it is optimal to invest if and only if $s_{e}=H .{ }^{11}$ Although investment is efficient, the entrepreneur cannot capture the whole project value because of $V C_{e}$ 's informational advantage: Competition is therefore imperfect. We explore in the next section what can be achieved when the entrepreneur approaches one VC first. We denote this strategy " exclusive talks".

\section{Exclusive talks}

Suppose now that the entrepreneur approaches one VC only. To ease notations, the latter is denoted $V C_{1}$, and his signal is $s_{1} \in\left\{H_{1}, L_{1}\right\} .{ }^{12}$ We consider a two-stage game. In the first stage, the entrepreneur bargains with $V C_{1}$. The first stage can be divided into an

\footnotetext{
${ }^{11}$ The optimal investment policy in our setting maximizes the expected monetary profits only. If one takes also into account the private benefit of the entrepreneur, the optimal investment policy may change: if private benefits are large, one may wish to finance projects which monetary NPV is negative, but which social NPV is positive. We abstract from these considerations because they do not alter qualitatively our results.

${ }^{12}$ Whether $V C_{1}$ is $V C_{e}$ or $V C_{u}$ depends on the optimal choice of the entrepreneur, and is determined at the end of the section.
} 
infinite number of time periods $t(t=0,1,2,3, \ldots$,$) . In each time period, the entrepreneur$ or $V C_{1}$ have the opportunity to move to a second stage by approaching the second $\mathrm{VC}$, denoted $V C_{2}$. In that case, the "shopping around" game described in section 4 starts.

The timing is the following. The first stage starts when the entrepreneur contacts $V C_{1}$ and $s_{1}$ is observed. The second stage starts if one agent terminates exclusivity. More precisely, if $V C_{1}$ makes the first offer, we have:

1. At $t=0, V C_{1}$ makes an offer. The entrepreneur accepts the offer, or terminates exclusivity, or

2. At $t=1$, the entrepreneur makes a counteroffer. $V C_{1}$ accepts the offer, or terminates exclusivity ${ }^{13}$, or

3. At $t=2, V C_{1}$ makes an offer, and the game continues as defined at $t=0$.

A similar alternating offers procedure takes place if the entrepreneur makes the first offer at $t=0$. This is similar to a Rubinstein-type model of bargaining in which the entrepreneur and $V C_{1}$ have the option to terminate exclusivity. The original feature of our modeling is that the value of these exit options is endogenous. It depends on the outcome of negotiation with the two VCs at the second stage. To determine this outcome, we look for a perfect Bayesian equilibrium (PBE) in which at each stage of the game, the strategies chosen by each agent are optimal given their beliefs, and the beliefs are computed from these equilibrium strategies using Bayes' rule.

The payoffs are as follows. If the agents agree on $\gamma_{1}$ at time $t(t=0,1,2,3, \ldots$,$) then the$ entrepreneur obtains $\beta^{t} q\left(H_{1}\right) p\left(\gamma_{1} R+B\right)$ where $\beta<1$ reflects entrepreneur's impatience and $V C_{1}$ gets $q\left(H_{1}\right) p\left(1-\gamma_{1}\right) R-I .{ }^{14}$ If they do not reach an agreement because one

\footnotetext{
${ }^{13}$ For sake of symmetry, we assume that $V C_{1}$ can also break exclusivity. Results are unchanged if only the entrepreneur can approach a competitor.

${ }^{14} \mathrm{We}$ assume that only the entrepreneur is impatient but results do not change if both agents are impatient.
} 
agent opts out at time $t$, they both obtain their outside option, i.e. their payoff following non exclusive negotiations. The key element to define their outside option payoffs, and thus the issue of the exclusive talks period, is the belief that $V C_{2}$ assigns to the event that $V C_{1}$ has received a high signal when the game gets to the second (non exclusive negotiation) stage. Indeed $V C_{2}$ faces an inference problem: He can be approached either because the first venture capitalist observed a low signal (no negotiation takes place) or because exclusive negotiation breaks down. Denote $\delta$ the probability that $V C_{2}$ assigns to the event that exclusive negotiation breaks down. The higher $\delta$, the higher $V C_{2}$ 's belief that the quality of the project is good. This modifies $V C_{2}$ ' s equilibrium strategy: $V C_{2}$ bids more aggressively as $\delta$ approaches 1 when the game reaches the second stage. In turn, the entrepreneur's (resp. $V C_{1}$ 's ) outside option payoff increases (resp. decreases) with $\delta$. The next propositions characterize the equilibrium values of $\delta$ and $\gamma_{1}$.

Proposition 2 There exists an equilibrium such that $V C_{1}$ makes an offer when $s_{1}=H$ and no offer when $s_{1}=L, \delta^{*}=0$ and $\gamma_{1}^{*}=0$.

When $\delta=0$, an agreement with $V C_{1}$ occurs at $t=0$ and exclusive negotiation succeeds. $V C_{2}$ believes that he is approached only when $V C_{1}$ has received a low signal, and that he faces no competing bid if he makes an offer. As a consequence, if $V C_{2}$ is $V C_{e}$, his best response is to offer $\gamma_{e}=0$ (monopoly offer), and if $V C_{2}$ is $V C_{u}$, his best response is to offer nothing, i.e. $\gamma_{u}=\emptyset$. Because of $V C_{2}$ 's best response, $V C_{1}$ can capture the project NPV at the second stage. The outside option of the entrepreneur at $t=0$ reduces to $\beta q\left(H_{1}\right) p B$ and the outside option of $V C_{1}$ is $q\left(H_{1}\right) p R-I$. In other words, the entrepreneur and $V C_{1}$ 's outside options are their off the equilibrium path pay-offs given $V C_{2}$ 's equilibrium belief. At the first stage, they both agree on a partition that leaves them at least their outside option.

Impatience ensures that the decision to accept an offer or to terminate exclusivity is taken at $t=0$ or $t=1$ of the first stage. 
Proposition 3 There is no equilibrium such that $V C_{1}$ makes an offer when $s_{1}=H$ and no offer when $s_{1}=L$, and such that the entrepreneur terminates exclusivity with positive probability.

When $\delta>0, V C_{2}$ believes that exclusive negotiation breaks down at $t=0$ with positive probability. ${ }^{15}$ An equilibrium with $\delta>0$ can only exist if the second signal is valuable enough so that the surplus shared between $V C_{1}$ and the entrepreneur is larger at the second stage than at the first stage. Intuitively, this can only happen if $V C_{2}$ is $V C_{e}$. But, as illustrated in proposition $1, V C_{e}$ is able to capture part of the project surplus thanks to his informational advantage. We show in the appendix that, because of $V C_{e}$ 's market power, the entrepreneur and $V C_{1}$ always have an incentive to negotiate at the first stage. For that reason, exclusive negotiation never fails in our setting, and equilibria with $\delta>0$ cannot be sustained.

Propositions 2 and 3 focus on separating equilibria (i.e. such that $V C_{1}$ makes a different offer when $s_{1}=H$ and when $s_{1}=L$ ). It is useful to discuss whether pooling equilibria can also be sustained. Observe first that, given that the project initial NPV is negative, such equilibria cannot be sustained if first stage negotiation succeeds with positive probability. We must therefore have $\delta=1$ in which case the game boils down to the shopping around game. For that reason, we rule out such equilibria when determining the entrepreneur's optimal strategy in section 6.

Proposition 4 If the entrepreneur decides to initiate exclusive talks, he always approaches $V C_{u}$ first.

The proof of proposition 4 is straightforward. Proposition 2 states that the entrepreneur accepts the offer $\gamma_{1}^{*}=0$ at the negotiation stage. The second stage occurs only when

\footnotetext{
${ }^{15} \mathrm{Or}$ at $t=1$ if the entrepreneur makes the first offer.
} 
$s_{1}=L$. This implies that after observing $s_{2}=H, V C_{2}$ offers 0 (monopoly offer) if he is $V C_{e}$, and $\emptyset$ if he is $V C_{u}$. To maximize his utility, the entrepreneur thus maximizes the probability to obtain financing. If he approaches $V C_{u}$ first, he is financed with probability $\operatorname{Pr}\left(H_{u}\right)+\operatorname{Pr}\left(H_{e}, L_{u}\right)$ while he is financed with probability $\operatorname{Pr}\left(H_{e}\right)$ if he approaches $V C_{e}$ first. ${ }^{16}$ See that:

$$
\operatorname{Pr}\left(H_{u}\right)+\operatorname{Pr}\left(H_{e}, L_{u}\right)=\operatorname{Pr}\left(H_{e}\right)+\operatorname{Pr}\left(H_{u}, L_{e}\right)>\operatorname{Pr}\left(H_{e}\right)
$$

We conclude this section by exploring the efficiency of the investment decision in the exclusive talks game.

Corollary 2 There is over-investment in the exclusive talks game, in the sense that all positive NPV projects are financed, but some negative NPV projects obtain financing.

Corollary 2 follows directly from the proof of Proposition 4. The entrepreneur is financed when either $V C_{u}$ or $V C_{e}$ observes a high signal, while it is optimal to finance projects if and only if $s_{e}=H$.

Section 4 states that optimal investment can be achieved when the entrepreneur decides to shop around. This raises the question why the entrepreneur might prefer an inefficient exclusive negotiation strategy. See that because of the superior information of $V C_{e}$, the entrepreneur cannot grab the total project value in any fund raising strategy. This might bias his choice towards inefficient outcomes. This question is explored in the next section.

\footnotetext{
${ }^{16}$ This result holds because the entrepreneur cares only about his expected private benefit which does not depend on the VCs level of experience. Section 8 discusses how this result changes if VCs can add value to the venture.
} 


\section{Entrepreneur's optimal negotiation strategy}

In this section, we analyze which negotiation strategy is chosen by the entrepreneur in equilibrium. To do this, we compare the entrepreneur's expected utility in both games, and obtain the following proposition.

Proposition 5 If the level of private benefit B is sufficiently low, in the sense that:

$$
B \leq \frac{\operatorname{Pr}\left(H_{e}\right) q\left(H_{e}\right) R\left(1-\frac{I}{q\left(H_{u}\right) p R}\right)}{\operatorname{Pr}\left(H_{u}\right) q\left(H_{u}\right)-\operatorname{Pr}\left(H_{e}\right) q\left(H_{e}\right)+\beta \operatorname{Pr}\left(L_{u}, H_{e}\right) q\left(L_{u}, H_{e}\right)}
$$

the entrepreneur prefers to shop around. Otherwise, he prefers to engage exclusive talks.

Proposition 5 implies that when the entrepreneur values mostly monetary profits, he prefers to be able to shop around. The main reason is that the outcome of the shopping around strategy is efficient, while that of exclusive talks is not. The value of funded projects is larger and the entrepreneur obtains a sufficiently large fraction of it to prefer the most efficient strategy. The important result is when the entrepreneur's private benefit becomes large. Then the entrepreneur's choice is biased towards the strategy that maximizes the probability to obtain funding, namely exclusive talks. This is the case because competition between VCs is imperfect, so that the entrepreneur does not capture the full project value. If he decides to shop around, the entrepreneur's project is funded with probability $\operatorname{Pr}\left(H_{e}\right)$, while it is funded with probability $\operatorname{Pr}\left(H_{e}\right)+\operatorname{Pr}\left(H_{u}, L_{e}\right)$ with exclusive

negotiation (see Corollary 2). When $B$ increases, the entrepreneur is willing to abandon a fraction of the project's cash-flows to increase his expected private benefit.

We explore below how the optimal negotiation strategy of the entrepreneur affects the deal flow and profitability of the VC industry.

Proposition 6 When $B$ is low in the sense that condition (4) holds, the deal flow of the two VCs is large, and only $V C_{e}$ earns positive expected profits. As $B$ increases in the 
sense that condition (4) does not hold any more, the level of expected profits of $V C_{u}$ increases, while that of $V C_{e}$ decreases. Also, $V C_{e}$ 's deal flow decreases.

Clearly, the two VCs are not indifferent to the entrepreneur's strategy choice. Because of his informational advantage, $V C_{e}$ strictly prefers that the entrepreneur shops around: In equilibrium only he finances projects. With exclusive talks, $V C_{e}$ only receives deals that have been rejected by his competitor, which lowers his deal flow and his expected profit. At the opposite, $V C_{u}$ strictly prefers exclusive talks, because he can offer deals without suffering from the winner's curse. An interesting result is that even though $V C_{u}$ 's signal is redundant, $V C_{u}$ finances projects in equilibrium (when negotiation occurs). This explains why different types of VCs co-exist in the industry.

Proposition 6 also suggests that different types of VCs potentially attract different types of entrepreneurs. Low-private benefit entrepreneurs send their projects to both inexperienced and experienced VCs, while high-private benefit entrepreneurs favor less experienced VCs.

\section{Empirical predictions}

Our focus on the entrepreneur's optimal negotiation strategy allows to derive unique empirical predictions regarding the number of offers received, the characteristics of the deals proposed by VCs, as well as the equilibrium performance of different VCs. We confront below these predictions to existing evidence and provide additional tests of our theoretical framework.

The first set of empirical predictions relates the level of private benefits of entrepreneurs to deal characteristics such as the number of offers received, or the venture valuation obtained. The model predicts that when $B$ is low, the entrepreneur optimally chooses to 
shop around, while he prefers exclusive negotiation when $B$ is high. We thus expect the number of offers received to be smaller when entrepreneurs' private benefit is high. To assess the relevance of this result, the empirical challenge is to measure the level of private benefit of entrepreneurs. One possibility is to interpret private benefits as future reputation gains if the venture succeeds. Success makes entrepreneurs more visible, increases their perceived talent, and expands the set of future job opportunities. ${ }^{17}$ Reputation gains are likely to be higher for young entrepreneurs with no track record or media coverage. An implication of the model is that young or unknown entrepreneurs (as measured by their media coverage for instance) are more likely to engage in exclusive negotiation and receive only one offer. A related implication of this result is that high private benefit entrepreneurs should obtain worse financing conditions (i.e. a lower price) than low private benefit entrepreneurs. Consistent with the above prediction, Hsu (2004) documents that pre-money valuations are significantly lower in single offer deals than in multiple offer deals. However, the link between the level of private benefits and the price obtained by entrepreneurs has, to our knowledge, not been tested.

Second, the model allows to relate the number of offers received by entrepreneurs to the expected level of experience of VCs offering deals. Hsu (2004) finds that the average level of experience of VCs is significantly lower when entrepreneurs receive a single offer, compared to when they receive several offers. To measure the average level of experience, Hsu (2004) attributes the value zero to VCs below the median level of experience of their industry, and the value one to VCs above the median. Our model predicts that the average level of experience when a single offer is received is: $\operatorname{Pr}\left(H_{u}\right) u+\operatorname{Pr}\left(H_{e}, L_{u}\right) e$ while it is $\frac{u+e}{2}$ when two offers are received. Following Hsu's characterization of experience, and attributing the value 0 to offers stemming from $V C_{u}$ and 1 to offers stemming from $V C_{e}$,

\footnotetext{
${ }^{17}$ Falato, Li, and Milbourn (2010) document that CEO pay includes a talent premium.
} 
our model is consistent with Hsu's observation if $\operatorname{Pr}\left(H_{e}, L_{u}\right)<\frac{1}{2}$. This is always the case when $q_{0}<\frac{1}{2}$, which is very likely for innovative projects. ${ }^{18}$

Last, for each negotiation strategy, our results predict that the relative financial performance of more and less experienced funds varies, because their financial offers and selection strategy vary. Proposition 6 states that the expected profit of experienced (resp. less experienced) VCs decreases (resp. increases) when private benefits increase. It is not easy though to observe the performance of a single fund over different market environments, usually because venture capital funds operate in specialized markets and geographic areas. To provide testable predictions of these results, we need to assess the relative performance of each fund, in each competitive regime. Also, empirical evidence on the performance of venture capital funds usually measures the profitability of the realized investments. We thus need to compute VCs expected profits, conditional on financing taking place. The next proposition summarizes these findings.

Proposition 7 In the shopping around strategy, $V C_{e}$ earns higher profit on investment than $V C_{u}$. In the exclusive talks strategy, $V C_{e}$ 's profit on investment can be larger or smaller than $V C_{u}$ 's.

The intuition of proposition 7 is the following. Only $V C_{e}$ earns positive expected profit if both VCs compete to finance the entrepreneur. As a consequence, the profit on investment is nul for $V C_{u}$, and positive for $V C_{e}$. Things are more complicated under exclusive talks, because the two VCs earn positive expected profits. The relative profitability of the two VCs depends on two elements. On the one hand, $V C_{u}$ has the advantage to play first, and to finance all projects for which he receives a high signal. On the other hand, $V C_{e}$ has a better screening ability, which may increase his profitability. Our model

\footnotetext{
${ }^{18}$ Bergemann, Hege, and Peng (2009) estimate that the failure rate of US venture capital investments is close to $60 \%$. Given the screening process of VC investments, the ex ante probability of failure of innovative projects is much above $60 \%$.
} 
thus predicts that more experienced VCs perform better when competition is intense, and private benefits are low, while this needs not be the case when competition is less severe. These results speak to the empirical findings of Kaplan and Schoar (2005), and Hege et al. (2006). While the former document some persistence in VC funds performance in the US, suggesting that more experienced or skilled VCs are able to generate larger returns, Hege et al. (2006) suggest that US VCs do not outperform European VCs when investing in European deals. Our model can reconcile the two by showing that experience alone cannot explain profitability: One needs to consider also the nature of competition. ${ }^{19}$

\section{Robustness}

We assume that the project has a positive NPV conditional on $s_{e}=H$ and negative otherwise. This gives a strong informational advantage to the experienced VC. Consider instead that the project has a positive NPV conditional on any high signal. This implies that $N P V_{0}>0$, which reduces the winner's curse of the less experienced VC. This modifies the shopping around equilibrium, by inducing $V C_{u}$ not to always withdraw his offer after observing a high signal. It is easy to show that for some parameter values, it can also lead both VCs to earn strictly positive expected profits. An important consequence is that the entrepreneur now has no incentive to engage in exclusive talks, because this strategy cannot increase his probability to obtain financing. The result of Bulow and Klemperer (1996) that competition leads to higher profits for the entrepreneur then applies. However, the assumption that the initial project NPV is positive does not fit well the situation of early-stage financing where a large fraction of ventures ultimately fail. In

\footnotetext{
${ }^{19}$ An alternative explanation to reconcile these two results is that US VCs are better at investing at home than abroad. This effect has been documented for analysts by Malloy (2005). Note however that if geography is the only determinant of performance, european VCs should perform better at home than their US counterparts for the same level of experience.
} 
these industries, we expect exclusive talks to occur more frequently. In the model, there is exactly one experienced and one unexperienced VC. If we allow for more than two VCs, the results depend on whether there still exists one VC with superior information compared to the others. If this is still the case (for instance, if there is one experienced, and several unexperienced VCs), the results are unchanged: Only the experienced VC makes positive profits when the entrepreneur shops around and exclusive negotiation still increases the probability for the entrepreneur to obtain financing. If however several experienced VCs are active on the market, their profits fall down to zero when they all compete for financing, as shown by Broecker (1990). With homogenous VCs, the efficient investment policy is to finance a project if and only if sufficiently many high signals are observed. ${ }^{20}$ It can thus still be the case that the entrepreneur prefers exclusive talks that leads to inefficiently too many projects financed when his private benefit is high. The main difference with our analysis relies on the level of profits achieved by VCs in the economy, and on the corresponding empirical predictions.

If we introduce a cost to generate each VC's signal, the results of the model are qualitatively unchanged but VCs' strategies in the shopping around game are modified. To ensure participation of all VCs and thus the existence of an equilibrium, the unexperienced VC has to make positive expected profits. We can construct a mixed strategy equilibrium (see Milgrom and Weber (1983), von Thadden (2004) or Hauswald and Marquez (2003)) such that the experienced VC makes a monopoly offer with a positive probability and the unexperienced VC provides financing with positive probability. In this equilibrium, both VCs make positive profits, and a costly signal does not impede their participation (provided that the cost is not too high). In the exclusive talks game, both VCs make positive profits: They agree to participate if obtaining a signal is (not too) costly.

\footnotetext{
${ }^{20}$ Therefore, observing one high signal is not sufficient to ensure that a project has a positive NPV.
} 
Last, the result of proposition 4 (that the entrepreneur commits to exclusive talks with the unexperienced VC) relies on the assumption that the experienced VC does not add value to the venture. If we instead assume that the level of experience of VCs modifies the level of private benefit of the entrepreneur, ${ }^{21}$ the entrepreneur's decision results from a new trade-off. By approaching the unexperienced VC first, the entrepreneur increases the probability to obtain financing. But by approaching the experienced VC first, he increases his private benefit. When the latter effect dominates, the entrepreneur negotiates with $V C_{e}$ first. But see that this rules out equilibria with exclusive talks. Indeed, by shopping around, the entrepreneur captures a larger fraction of the expected cash-flows and obtains the same financing probability as when he negotiates with $V C_{e}$ first. It turns out that if exclusive negotiation arises in equilibrium, the unexperienced VC is necessarily contacted first.

\section{Conclusion}

In this paper, we investigate how competition takes place in the venture capital industry, emanating from entrepreneurs' negotiation strategy. We consider a model whereby a cash-poor entrepreneur proposes an investment project to venture capitalists. We compare the utility that the entrepreneur can obtain when he proposes his project to two VCs at the same time and when he starts exclusive negotiations with one VC only. Some important assumptions drive the results of the model. Firstly, venture capitalists are able to extract private information on the true value of the project, which constitutes an informational advantage when dealing with the entrepreneur. To feature in a realistic way the heterogeneity in the venture capital industry, we assume that VCs have different signal

\footnotetext{
${ }^{21}$ For instance, more experienced VCs can more easily introduce new partners in the future, thereby increasing the continuation value of the venture, as suggested in Hsu (2004).
} 
precisions, which make them more or less vulnerable when competing with each other. As a consequence, their equilibrium strategies and expected profits are different. Secondly, the entrepreneur enjoys non monetary benefits when his project is implemented. When deciding his optimal negotiation strategy, he cares not only about his expected monetary profits, but also about his expected private benefits. This affects the efficiency of the investment decision, and the performance of the industry.

One insight of the model is that the entrepreneur can hardly use the threat of competition to extract profit when negotiating with one VC only. Indeed, the entrepreneur's outside option when engaging in exclusive negotiation depends on the subsequent VC's beliefs about why he is approached. This inference problem gives rise to an equilibrium in which the entrepreneur cannot capture any monetary profit when engaging in exclusive negotiation. When his private benefit is large, he may still prefer the exclusive negotiation strategy because it leads to (inefficiently) too many projects financed: The probability to obtain financing is thus larger than in the case where the entrepreneur initiates talks with both VCs. Therefore, the optimal negotiation strategy of the entrepreneur depends on his level of private benefit. This has consequences for both the deal flow and performance of the venture capital industry. When the entrepreneur's private benefit is small, all VCs experience a high deal flow, and only the experienced VC makes positive expected profits. When the private benefit is large, the entrepreneur prefers to start negotiating with the unexperienced VC first. This raises the latter's expected profit, and reduces both the deal flow and the expected profit of the experienced VC. Finally, this strategy reduces efficiency in the sense that some inefficient projects are financed. 


\section{Appendix}

\section{Proof of Lemma 1}

Let us prove that $\hat{\gamma}_{e}>\hat{\gamma}_{u}$. This is equivalent to:

$$
I\left(\frac{q\left(H_{e}\right)}{q\left(H_{u}\right)}-1\right)>\operatorname{Pr}\left(L_{u} \mid H_{e}\right)\left[q\left(H_{e}, L_{u}\right) p R-I\right]
$$

Note that:

$$
\frac{q\left(H_{e}\right)}{q\left(H_{u}\right)}=\frac{e q_{0}\left[u q_{0}+(1-u)\left(1-q_{0}\right)\right]}{u q_{0}\left[e q_{0}+(1-e)\left(1-q_{0}\right)\right]}
$$

and $\operatorname{Pr}\left(L_{u} \mid H_{e}\right)\left[q\left(H_{e}, L_{u}\right) p R-I\right]=\frac{e(1-u) q_{0}}{e q_{0}+(1-e)\left(1-q_{0}\right)} p R-I \frac{e(1-u) q_{0}+u(1-e)\left(1-q_{0}\right)}{e q_{0}+(1-e)\left(1-q_{0}\right)}$.

Using (6) and (7) into (5) yields:

$$
e\left(I-q_{0} p R\right) u+I\left(1-q_{0}\right)>I\left(1-q_{0}\right) u .
$$

Condition (8) is always true since $e>u$ and $N P V_{0}<0$ hence $\hat{\gamma}_{e}>\hat{\gamma}_{u}$.

\section{Proof of proposition 1}

Denote $\phi_{u}\left(\right.$ resp. $\left.\phi_{e}\right)$ the probability that $V C_{u}\left(\right.$ resp. $V C_{e}$ ) maintains his offer. Define $\lambda \in[0,1]$ the probability that $V C_{u}$ 's offer is chosen when $V C_{e}$ makes the same offer. Consider the following equilibrium candidate:

- $V C_{u}$ proposes $\hat{\gamma}_{u}$ and always withdraws his offer, unless the entrepreneur shows him an offer $\gamma_{e}<\hat{\gamma}_{u}$

- $V C_{e}$ proposes $\hat{\gamma}_{u}$ and withdraws his offer if and only if $s_{e}=L$. 
- The entrepreneur always shows $V C_{e}$ 's offer to $V C_{u}$.

Given the players' strategy, $V C_{u}$ has no incentive to deviate. He makes negative expected profits if he maintains his offer after $s_{u}=L$. He makes negative profits if he maintains his offer after $s_{u}=H$ when $\gamma_{e}=\hat{\gamma}_{u}$ if $\lambda<1$, and he is indifferent if $\lambda=1$.

$V C_{e}$ has no incentive to deviate either. If he proposes $\gamma_{e}<\hat{\gamma}_{u}$, his expected profit is:

$$
\operatorname{Pr}\left(L_{u} \mid H_{e}\right)\left[q\left(H_{e}, L_{u}\right) p R-I\right]
$$

If he offers $\hat{\gamma}_{u}$, his expected profit is: $I\left(\frac{q\left(H_{e}\right)}{q\left(H_{u}\right)}-1\right)$. We already proved above that $I\left(\frac{q\left(H_{e}\right)}{q\left(H_{u}\right)}-1\right)>$ $\operatorname{Pr}\left(L_{u} \mid H_{e}\right)\left[q\left(H_{e}, L_{u}\right) p R-I\right]$ since $\hat{\gamma}_{u}<\hat{\gamma}_{e}$.

Last, the entrepreneur is indifferent between showing $V C_{e}$ 's offer or not, when $\gamma_{e}=\hat{\gamma}_{u}$. He then shows it in equilibrium.

\section{Proof of proposition 2}

Consider the equilibrium candidate in which $\delta=0$ and $V C_{1}$, whatever his level of experience, plays $\gamma_{1}=\emptyset$ if $s_{1}=L$, and $\gamma_{1}=0$ if $s_{1}=H$.

We know from the Rubinstein's model (see for instance Muthoo (99)) that in the negotiation model with outside options, there exists a unique subgame perfect equilibrium (SPE) in which agreement is reached at time 0 . In equilibrium, the negotiations do not break down in disagreement and players do not take up their outside option, which implies $\delta=0$. However, the presence of outside options do influence the equilibrium partition: each player cannot obtain more than his outside option at the negotiation stage. Also, the SPE does not depend on which player makes the first offer at time 0 .

Let us now determine the outside option payoffs when $\delta=0: V C_{2}$ believes that any offer by $V C_{1}$ is accepted by the entrepreneur. If $V C_{2}$ is contacted at the second stage of the game, his 
equilibrium belief is thus that $s_{1}=L$. Given his belief, he plays $\gamma_{2}=\emptyset$ if $s_{2}=L$, and, if $s_{2}=H$, he plays $\gamma_{2}=\emptyset$ if $V C_{2}$ is $V C_{u}$, or $\gamma_{2}=0$ if he is $V C_{e}$. At the second stage, $V C_{1}$ 's optimal response is to offer $\gamma_{1}=\epsilon$ (if he is $V C_{u}$ ) or 0 (if he is $V C_{e}$ ). The outside option payoff of the entrepreneur then reduces to $\beta q\left(H_{1}\right) p B$ (if $V C_{1}$ is $V C_{e}$ ) or $\beta q\left(H_{1}\right)\left(p B+\epsilon R\right.$ ) (if $V C_{1}$ is $\left.V C_{u}\right)$. $V C_{1}$ obtains $N P V\left(H_{1}\right)$ if he is experienced and $q\left(H_{1}\right) p(1-\epsilon) R-I$ if he is less experienced.

The unique SPE share obtained by $V C_{1}$ converges to $N P V\left(H_{1}\right)$ and the entrepreneur only obtains his private benefit $q\left(H_{1}\right) p B$. At equilibrium, this translates into $\gamma_{1}=0$.

\section{Proof of proposition 3}

Consider the equilibrium candidate in which $\delta>0$ and $V C_{1}$ plays $\gamma_{1}=\emptyset$ if $s_{1}=L$ and $\gamma_{1} \geq 0$ if $s_{1}=H$.

A necessary condition to sustain an equilibrium with $\delta>0$ is that it is an equilibrium strategy to reject any profitable offer of the other party. By profitable, we mean any offer that gives the other party at least the same expected payoff as that obtained if the offer is rejected and the second stage occurs. A necessary condition is thus that the joint surplus that the entrepreneur and $V C_{1}$ can share at the exclusive negotiation stage is smaller than their joint surplus if the second stage occurs. Were this not true, one party could make an offer such that she is indifferent between seeing her offer accepted, or rejected (and the second stage occurring). Then the other party would always prefer to accept the offer (by assumption, if the joint surplus of the two parties is larger at the first stage than at the second, and if one party makes an offer such that she is indifferent, the other party strictly gains by accepting the offer). We show below that this necessary condition can not be satisfied and thus that there is no equilibrium in which the entrepreneur rejects $V C_{e}$ 's offer with probability $\delta>0$.

1) Assume that the entrepreneur contacts $V C_{e}$ first. The maximum feasible bid of $V C_{u}$ now 
depends on $\delta$. The higher $\delta$, the more confident $V C_{u}$ is about the project quality and the higher his competitive bid is. Denote $q\left(H_{u}, \delta\right)$ the probability that the quality of the project is good given that $V C_{u}$ has observed a high signal and given $V C_{u}$ 's belief $\delta>0$. We have:

$$
q\left(H_{u}, \delta\right)=\frac{q_{0} u(e \delta+(1-e))}{q_{0} u(e \delta+(1-e))+\left(1-q_{0}\right)(1-u)(e+(1-e) \delta)},
$$

and $\hat{\gamma}_{u}(\delta)=\frac{N P V\left(H_{u}, \delta\right)}{q\left(H_{u}, \delta\right)}$ is increasing with $\delta$. This implies that $\hat{\gamma}_{u}(\delta)<\hat{\gamma}_{e} \forall \delta$.

If the game reaches the second stage, the strategy of $V C_{u}$ is to propose $\hat{\gamma}_{u}(\delta)$ and withdraw his offer unless he observes $s_{u}=H$, and the entrepreneur shows him an offer $\gamma_{e}<\hat{\gamma}_{u}(\delta)$. Else, $V C_{u}$ makes negative expected profits. The strategy of $V C_{e}$ is then to propose $\gamma_{e}=\hat{\gamma}_{u}(\delta)$ and maintain it if $s_{e}=H$. Given $V C_{u}$ 's strategy, $V C_{e}$ has no incentive to deviate. If he deviates and announce $\gamma_{e}<\hat{\gamma}_{u}(\delta)$, his expected profit is: $\operatorname{Pr}\left(L_{u} \mid H_{e}\right)\left[q\left(H_{e}, L_{u}\right) p R-I\right]$, which is lower than his expected profit when announcing $\hat{\gamma}_{u}(\delta): I\left(\frac{q\left(H_{e}\right)}{q\left(H_{u}, \delta\right)}-1\right)$.

The surplus that the entrepreneur and $V C_{e}$ can share at the second stage is thus $\left(\beta\left(q\left(H_{e}\right) p\left(\hat{\gamma}_{u}(\delta) R+\right.\right.\right.$ $\left.B))+\left(1-\hat{\gamma}_{u}(\delta)\right) q\left(H_{e}\right) p R-I\right)$. See that this surplus is strictly lower than the surplus that the entrepreneur and $V C_{e}$ can share at the first stage $\left(q\left(H_{e}\right) p(R+B)-I\right)$ because $\beta<1$. This implies that $V C_{e}$ can always propose $\gamma_{e}$ such that he and the entrepreneur are both better off negotiating than going to the second stage. The equilibrium candidate in which $\delta>0$ does not exist.

2) Assume that the entrepreneur contacts $V C_{u}$ first. Again, the competitive bid of $V C_{e}$ depends on $\delta$ : $V C_{e}$ bids more aggressively as $\delta$ approaches 1 . When $V C_{e}$ believes that $V C_{u}$ 's offer is rejected with probability $\delta$, his maximum bid is defined as follows:

$$
\hat{\gamma}_{e}(\delta)=\frac{N P V\left(H_{e}, \delta\right)-\operatorname{Pr}\left(L_{u} \mid H_{e}, \delta\right)\left(q\left(H_{e}, L_{u}, \delta\right) p R-I\right)}{q\left(H_{e}, \delta\right) p R},
$$

and is increasing with $\delta . \hat{\gamma}_{e}(\delta)$ can then be larger or smaller than the competitive bid of $V C_{u}$ when $\delta<1$.

Consider first the values of $\delta$ such that $\hat{\gamma}_{u} \leq \hat{\gamma}_{e}(\delta)$. The strategies of the two VCs at the second 
stage are those defined in proposition 1 . The strategy of $V C_{u}$ is to propose $\hat{\gamma}_{u}$ and withdraw his offer unless the $V C_{e}$ shows him an offer $\gamma_{e}<\hat{\gamma}_{u}$ (and $\left.s_{u}=H\right) . V C_{e}$ then announces $\gamma_{e}=\hat{\gamma}_{u}$ and maintains it if $s_{e}=H$.

The expected utility of the entrepreneur if he terminates exclusive negotiation is thus

$$
E\left(U_{E}\right)=\beta \operatorname{Pr}\left(H_{e} \mid H_{u}\right) q\left(H_{e}, H_{u}\right) p\left(\hat{\gamma}_{u} R+B\right) .
$$

The joint profit that $V C_{u}$ and the entrepreneur can share under exclusive negotiation is $q\left(H_{u}\right) p(R+$ $B)-I$. See that

$$
\beta \operatorname{Pr}\left(H_{e} \mid H_{u}\right) q\left(H_{e}, H_{u}\right) p\left(\hat{\gamma}_{u} R+B\right)<q\left(H_{u}\right) p(R+B)-I
$$

which reduces to

$$
\beta \operatorname{Pr}\left(H_{e} \mid H_{u}\right) q\left(H_{e}, H_{u}\right)<q\left(H_{u}\right) \Leftrightarrow \beta e<1,
$$

which is always true. The equilibrium candidate in which $\delta>0$ and $\hat{\gamma}_{u} \leq \hat{\gamma}_{e}(\delta)$ does not exist. Consider next the values of $\delta$ such that $\hat{\gamma}_{u}>\hat{\gamma}_{e}(\delta)$. We know that $V C_{e}$ does not want to bid until $\hat{\gamma}_{u}$ since he can obtain a strictly higher expected payoff by bidding 0 each time he receives a high signal. This implies that $V C_{u}$ never bids above $\hat{\gamma}_{e}(\delta)$, and that he also earns positive expected profits. The equilibrium pure strategies defined in proposition 1 cannot constitute an equilibrium anymore. There exists a mixed strategy equilibrium (see Milgrom and Weber (1983), von Thadden (2004) and Hauswald and Marquez (2003)) in which, when $V C_{e}$ receives a high signal, with probability $x_{e}(\delta)$, he randomizes according to a continuous distribution $F_{e}(\gamma)$ on $\left[0, \hat{\gamma}_{e}(\delta)\right]$ and, with probability $\left(1-x_{e}(\delta)\right)$, he plays $\gamma_{e}^{*}=0$. When $V C_{u}$ receives a high signal, he randomizes according to a continuous distribution $F_{u}(\gamma)$ on $\left[0, \hat{\gamma}_{e}(\delta)\right]$. The expected profit of $V C_{e}$ is strictly positive and equal to $\operatorname{Pr}\left(L_{u} \mid H_{e}, \delta\right)\left(q\left(H_{e}, L_{u}\right) p R-I\right)$. The expected profit of $V C_{u}$ is also positive and equal to $\left(\left(1-\hat{\gamma}_{e}(\delta)\right) q\left(H_{u}\right) p R-I\right)$.

The expected utility of the entrepreneur is then equal to the project's social value given $V C_{u}$ 's 
signal, minus the expected profit of $V C_{u}$ under competition (denoted $E\left(\Pi_{V C_{u}}\right)$ ), minus the rent left to $V C_{e}$ when $s_{u}=H$ :

$$
\begin{aligned}
E\left(U_{E}\left(\hat{\gamma}_{u}>\hat{\gamma}_{e}(\delta)\right)\right)= & q\left(H_{u}\right) p(R+B)-I-\left(\left(1-\hat{\gamma}_{e}(\delta)\right) q\left(H_{u}\right) p R-I\right) \\
& -\operatorname{Pr}\left(H_{e} \mid H_{u}\right) E_{\gamma_{u}>\gamma_{e}}\left(\left(1-\gamma_{e}\right) q\left(H_{u}, H_{e}\right) p R-I\right)
\end{aligned}
$$

Clearly, $E\left(U_{E}\left(\hat{\gamma}_{u}>\hat{\gamma}_{e}(\delta)\right)+E\left(\Pi_{V C_{u}}\right)<q\left(H_{u}\right) p(R+B)-I\right.$. Therefore, $V C_{u}$ can propose $\gamma_{u}$ such that both he and the entrepreneur are better off negotiating than enforcing competition, and the equilibrium candidate in which $\delta>0$ and $\hat{\gamma}_{u}>\hat{\gamma}_{e}(\delta)$ does not exist.

Although the second signal increases the value of the project, the entrepreneur has to abandon a positive profit to $V C_{e}$ if he engages in non exclusive negotiation. As a consequence, there always exists an offer at the first stage, that grants the entrepreneur a strictly higher utility than what he can obtain at the second stage. Terminating exclusivity cannot be an equilibrium strategy.

\section{Proof of proposition 5}

When the shopping around strategy is chosen, the expected utility of the entrepreneur is equal to the total expected monetary profits, minus the expected profit of $V C_{e}$, plus the expected private benefit. Formally, we have:

$$
E\left(U_{E}\right)=\operatorname{Pr}\left(H_{e}\right) q\left(H_{e}\right)\left(\frac{q\left(H_{u}\right) p R-I}{q\left(H_{u}\right) p R} p R+p B\right)
$$

When the entrepreneur initiates exclusive talks, he obtains:

$$
E\left(U_{E}\right)=\operatorname{Pr}\left(H_{u}\right) q\left(H_{u}\right) p B+\beta \operatorname{Pr}\left(L_{u}, H_{e}\right) q\left(L_{u}, H_{e}\right) p B .
$$


Using equations (11) and (12), it follows that the entrepreneur prefers exclusive negotiation iff:

$$
B \geq \frac{\operatorname{Pr}\left(H_{e}\right) q\left(H_{e}\right) R\left(1-\frac{I}{q\left(H_{u}\right) p R}\right)}{\operatorname{Pr}\left(H_{u}\right) q\left(H_{u}\right)-\operatorname{Pr}\left(H_{e}\right) q\left(H_{e}\right)+\beta \operatorname{Pr}\left(L_{u}, H_{e}\right) q\left(L_{u}, H_{e}\right)} .
$$

\section{Proof of proposition 6}

Recall that the expected profit of $V C_{u}$ is strictly positive and equal to $\operatorname{Pr}\left(H_{u}\right)\left(q\left(H_{u}\right) p R-I\right)$ under exclusive talks, while it is zero when the entrepreneur shops around.

The expected profit of $V C_{e}$ is $\operatorname{Pr}\left(L_{u}, H_{e}\right)\left(q\left(H_{e}, L_{u}\right) p R-I\right)$ with exclusive talks. It is equal to $\operatorname{Pr}\left(H_{e}\right) I\left(\frac{q\left(H_{e}\right)}{q\left(H_{u}\right)}-1\right)$ when the entrepreneur approaches both VCs simultaneously.

We know from Lemma 1 that

$$
\operatorname{Pr}\left(H_{e}\right) I\left(\frac{q\left(H_{e}\right)}{q\left(H_{u}\right)}-1\right)>\operatorname{Pr}\left(H_{e}\right) \operatorname{Pr}\left(L_{u} \mid H_{e}\right)\left(q\left(H_{e}, L_{u}\right) p R-I\right) .
$$

Given that $\operatorname{Pr}\left(H_{e}\right) \operatorname{Pr}\left(L_{u} \mid H_{e}\right)=\operatorname{Pr}\left(L_{u}, H_{e}\right)$, we obtain that expected profits of $V C_{e}$ are higher in the shopping around strategy.

\section{Proof of proposition 7}

For a given offer, the expected profit on investment $(E \Pi(V C \mid I))$ is given by $E \Pi(V C \mid I)=$ $\frac{E \Pi(V C)}{p_{V C}(I)}$, where $p_{V C}(I)$ is the probability that $V C$ 's offer is accepted, and where $E \Pi(V C)$ is the expected profit on each offer. Note that total expected profits are simply obtained by multiplying $E \Pi(V C)$ by the probability to make an offer.

In the "shopping around" strategy, only $V C_{e}$ finances the entrepreneur at equilibrium. As a consequence, we have :

$$
E \Pi\left(V C_{e} \mid I\right)>E \Pi\left(V C_{u} \mid I\right)=0 .
$$


When the entrepreneur initiates exclusive negotiation, each offer is accepted with probability one $\left(p_{V C_{e}}(I)=p_{V C_{u}}(I)=1\right)$ and each VC offers $\gamma=0$. Profits on investment are then given by: $\Pi\left(V C_{u}\right)=q\left(H_{u}\right) p R-I$ and $\Pi\left(V C_{e}\right)=q\left(H_{e}, L_{u}\right) p R-I$.

$$
\Pi\left(V C_{e}\right)-\Pi\left(V C_{u}\right)=\left[q\left(H_{e}, L_{u}\right) p R-I\right]-\left[q\left(H_{u}\right) p R-I\right]
$$

Equation (14) reduces to

$$
\Pi\left(V C_{e}\right)-\Pi\left(V C_{u}\right)=\frac{e}{(1-e)}-\frac{u^{2}}{(1-u)^{2}}
$$

Equation (15) may be positive or negative, depending on parameter values.

Observe next that $\frac{\partial\left(\Pi\left(V C_{e}\right)-\Pi\left(V C_{u}\right)\right)}{\partial e}>0$ and that $\exists \varepsilon=\frac{(2 u-1) u(1-u)}{(1-u)^{2}+u^{2}}>0$ such that $\Pi\left(V C_{e}\right)>$ $\Pi\left(V C_{u}\right)$ when $e-u>\varepsilon$. 


\section{References}

Axelson, Ulf, 2007, Security design with investor private information, Journal of Finance 62, 2503-2520.

Bergemann, Dirk, Ulrich Hege, and Liang Peng, 2009, Venture capital and sequential investments, Cowles Foundation Discussion Papers 1682RR, Cowles Foundation for Research in Economics, Yale University.

Blanchflower, David, and Andrew Oswald, 1992, Entrepreneurship, happiness, and supernormal returns: Evidence from Britain and the U.S., NBER WP 4228.

Boone, Audra, and Harold Mulherin, 2007, How Are Firms Sold?, Journal of Finance 62, 847875.

Bottazzi, Laura, Marco Da Rin, and Thomas Hellmann, 2008a, Who are the active investors? Evidence from venture capital, Journal of Financial Economics 89, 488-512.

Bottazzi, Laura, Marco Da Rin, and Thomas Hellmann, 2008b, What role of legal system in financial intermediation? Theory and evidence, Discussion Paper 2008-30 Tilburg University, Center for Economic Research.

Broecker, Thorsten, 1990, Credit-worthiness tests and interbank competition, Econometrica 58, $429-452$.

Bulow, Jeremy, and Paul Klemperer, 1996, Auctions versus negotiations, American Economic Review 86, 180-194.

Casamatta, Catherine, 2003, Financing and advising: optimal financial contracts with venture capitalists, Journal of Finance 58, 2059-2086.

Casamatta, Catherine, and Carole Haritchabalet, 2007, Experience, screening and syndication in venture capital investments, Journal of Financial Intermediation 16, 368-398.

Cestone, Giacinta, 2006, Venture capital meets contract theory: risky claims or formal control?, CEPR Discussion Paper No. 3462.

Cestone, Giacinta, Josh Lerner, and Lucy White, 2007, The Design of syndicates in venture capi- 
tal, mimeo CSEF-University of Salerno.

Chan, Yuk-Shee, Daniel Siegel, and Anjan Thakor, 1990, Learning, corporate control, and performance requirements in venture capital contracts, International Economic Review 31, p. 365-381. Dessì, Roberta, 2005, Start-up finance, monitoring and collusion, RAND Journal of Economics $36,255-274$.

Falato, Antonio, Dan Li, and Todd Milbourn, 2010, To each according to his ability? The value of CEO talent?, mimeo Washington University in St. Louis.

Fenn, George, Nellie Liang, and Stephen Prowse, 1995, The economics of the private equity market, Washington board of Governors of the Federal Reserve System, Staff Study 168.

Garmaise, Mark, 2007, Informed investors and the financing of entrepreneurial projects, mimeo UCLA Anderson School of Management.

Gompers, Paul, 1995, Optimal investment, monitoring, and the staging of venture capital, Journal of Finance 50, 1461- 1489.

Gompers, Paul, 1996, Grandstanding in the venture capital industry, Journal of Financial Economics 42, 133-156.

Hamilton, Barton, 2000, Does entrepreneurship pay? An empirical analysis of the returns to selfemployment, Journal of Political Economy 108, 604-631.

Hauswald, Robert, and Robert Marques, 2003, Information technology and financial services competition, Review of Financial Studies 16, 921-948.

Hege, Uli, Fred́eŕic Palomino, and Armin Schwienbacher, 2006, Venture capital performance: the disparity between Europe and the United States, mimeo HEC Paris.

Hellmann, Thomas, 1998, The allocation of control rights in venture capital contracts, Rand Journal of Economics 29, 57-76.

Hellmann, Thomas, 2007a, Entrepreneurs and the process of obtaining resources, Journal of Economics and Management Strategy 16, 81-109.

Hellmann, Thomas, 2007b, The role of patents for bridging the science to market gap, Journal of Economic Behavior and Organization 63, 624-647. 
Hopp, Christian, and Finn Rieder, 2006, What drives venture capital syndication?, mimeo University of Konstanz.

Hsu, David, 2004, What do entrepreneurs pay for venture capital affiliation?, Journal of Finance $59,1805-1844$.

Inderst, Roman, and Holger Mueller, 2004, The effect of capital markets characteristics on the value of start-up firms, Journal of Financial Economics 72, 319-356.

Inderst, Roman, and Holger Mueller, 2006, Informed lending and security design, Journal of Finance 61, 2137-2162.

Kaplan, Steven, and Antoinette Schoar, 2005, Private equity performance: Returns, persistence, and capital flows, Journal of Finance 60, 1791-1823.

Kaplan, Steven, and Per Strömberg, 2004, Characteristics, Contracts, and Actions: Evidence from Venture Capitalist Analyses, Journal of Finance 59, 2177-2210.

Landier, Augustin, 2005, Entrepreneurship and the Stigma of Failure, mimeo New York University. Lerner, Josh, 1994, The syndication of venture capital investments, Financial Management 23, $16-27$.

Malloy, Christopher, 2005, The Geography of Equity Analysis, Journal of Finance 60, 719-755.

Milgrom, Paul and Robert J. Weber, 1982, A Theory of Auctions and Competitive Bidding, Econometrica 50, 1089-1122.

Moskowitz, Tobias, and Annette Vissing-Jorgensen, 2002, The returns to entrepreneurial investment: A private equity premium puzzle?, American Economic Review 92, 745-778.

Muthoo, Abhinay, Bargainig Theory with Applications, Cambridge University Press.

Peyrache, Eloic, and Lucia Quesada, 2006, Financial contracting with an informed investor, mimeo University Torcuato di Tella and HEC Paris.

Rajan, Raghuram, 1992, Insiders and outsiders: The choice between informed and arm's-length debt, Journal of Finance 47, 1367-1400.

Renucci, Antoine, 2008, Bargaining with Venture Capitalists when Non-Supportive Financing is an Option, discussion paper DRM-FINANCE 2008-8, University Paris Dauphine. 
Repullo, Rafael, and Javier Suarez, 2004, Venture capital finance: a security design approach, Review of Finance 8, 75-108.

Sahlman, William, 1988, Aspects of financial contracting in venture capital, Journal of Applied Corporate Finance 1, 23-36.

Sahlman, William, 1990, The structure and governance of venture capital organizations, Journal of Financial Economics 27, 473-522.

Schmidt, Klaus, 2003, Convertible securities and venture capital finance, Journal of Finance 58, 1139-1166.

Sharpe, Steven, 1990, Asymmetric information, bank lending and implicit contracts: A stylized model of customer relationships, Journal of Finance 45, 1069 ?1087.

Thakor, Anjan, 1996, Capital requirements, monetary policy, and aggregate bank lending: Theory and empirical evidence, Journal of Finance 51, 279-324.

von Thadden, Ernst-Ludwig, 2004, Asymmetric Information, Bank Lending and Implicit Contracts: the Winner's Curse, Finance Research Letters 1, 11-23. 